Journal of Teacher Education for Sustainability, vol. 18, no. 2, pp. 21-40, 2016

\title{
Assessing the Infusion of Sustainability Principles into University Curricula
}

\author{
Michele Biasutti \\ University of Padova, Italy \\ Theodora De Baz \\ Hashemite University, Jordan \\ Hala Alshawa \\ Amman University of Jordan, Jordan
}

\begin{abstract}
The current paper presents the assessment of the infusion of sustainability principles into university curricula at two Jordanian universities. The peer review process of revising the curricula infusing sustainability principles is also discussed. The research methodology involved quantitative methods to assess the revised courses. The results revealed the following: the most relevant ESD themes in the revised curricula were "human connections to the physical and natural world", and "ethics/values". The most relevant ESD topics were: "sustainable production/consumption" and "health promotion". The most infused ESD pillars (competencies) were: "learning to know" and "learning to do". The most relevant ESD principles were: "practiced locally" and "responds through applied learning". The findings offered a rich scenario of the strategies applied by the university professors in revising the curricula, providing evidence of a mental attitude to adopt ESD strategies, as well as a goal-oriented approach in curriculum planning. The paper also discusses the implications of the study results for syllabus revision and development, as well as the refinement of the teaching methods that focus on infusing sustainability into university curricula.
\end{abstract}

Keywords: education for sustainable development, higher education, professional development, curricula revision, Reorient University Curricula to Address Sustainability (RUCAS)

\section{Introduction}

A key outcome of the United Nations World Summit on Sustainable Development was the establishment of a special United Nations Decade of Education for Sustainable Development (UNDESD) from 2005 to 2014. The central concern of the UNDESD was to integrate principles, values, and practices of sustainable development into all aspects of teaching and learning (Biasutti \& Surian, 2012; Pipere, Veisson, \& Salìte, 2015). 
Higher education institutions in the Arab region faced challenges related to the slow progress of the implementation of the UNDESD. This was due to a number of barriers such as limited staff awareness and expertise, lack of appropriate curricula, traditional teaching methods and materials to address Education for Sustainable Development (ESD). In response to these needs and priorities, the three-year Tempus project coordinated by Prof. Makrakis of Crete University, entitled Reorient University Curricula to Address Sustainability (RUCAS), was launched on October 2010. The RUCAS project was funded by the European Commission and aimed to support the development of ESD in six higher education institutions from the Arab region (Egypt, Jordan, and Lebanon), with the assistance of five EU higher education institutions from France, Greece, Ireland, Italy, and Sweden. The main goals of the project were: to build capacity among university teaching staff to embed ESD in curricula and pedagogy, to review and revise undergraduate curricula to address ESD in line with Bologna and Lisbon processes, and to assist the coordination and dissemination of ESD policy, research, curriculum reform, and practice relating to ESD in the partner institutions (RUCAS, 2011). In addition, it was expected that the higher education institutions from the Arab region participating in the project would function as role models in the region.

The current study focuses on the assessment of the infusion of sustainability into the curricula at two Jordanian universities (which will be referred to as University 1 and University 2) in agreement with the UNDESD. The background of the revision process and course implementation is initially presented. The experimental part focuses on the assessment of the revised courses.

\section{Background of the Revision Process and Course Implementation at University 1}

Introducing ESD into University 1 curricula involved reviewing existing courses and teaching methods to address issues that were pertinent to education for sustainability. For this purpose, the infusion process was adopted, which implied re-orienting the existing courses and approaches to teaching and learning, so that concepts, contexts, principles, practices, and values of ESD were addressed (Kostoulas-Makrakis, 2010). The process entailed the integration of sustainability content, skills, methods and competencies into the existing course, not by adding another course, or jeopardising its integrity, where each discipline could be infused by sustainability principles, concepts and methods.

The infusion process was accomplished by faculty teaching staff who worked independently and in teams during the following three workshops: the first regional workshop was held in Beirut, Lebanon on 23-25 October 2011; the second regional workshop was held in Cairo, Egypt on 7-9 January 2012; and the third regional workshop was held in Amman, Jordan on 17-19 April 2012. The focus of the first workshop held in Beirut was on training the participants on innovative teaching and learning methods and the processes for revising university curricula to address sustainability. The second workshop held in Cairo focused on discussing and reflecting on the revised syllabi developed by each educator to infuse sustainability in the institution's curricula. The emphasis of the third workshop that took place in Amman was placed on examining the implementation process of the revised courses.

At University 1, the areas of curriculum revision included: educational sciences, social sciences, engineering, information technology, and applied sciences. The process 
began with revising the learning goals and objectives addressed in the templates of course syllabi to find out whether they were clearly stated in the different subject areas. The next step was going over the course learning outcomes and checking whether the sustainability competencies were addressed and aligned with the five pillars of sustainability competencies: learning to know, learning to do, learning to be, learning to live together, and learning to transform oneself and society (Delors, 1996). The third step was to determine the extent to which the course outcomes focused on the following critical sustainability themes: scale-time, human connections to the physical and natural world, ethics and values, functioning of natural systems, technological and economic relationships to sustainability, and motivating environmentally sustainable behaviour. Through the revision process, emphasis was placed to ensure that the themes included within the courses fit the environmental, social, and economical aspects of sustainability contextualised in the local and regional conditions. To effectively implement the courses, the following ESD principles or criteria were considered:

- Interdisciplinary, cross-disciplinary, and holistic approaches;

- Approaches based on authentic learning;

- Value-driven and ethics based principles;

- Approaches focused on experiential, constructivist, and transformative learning;

- Multi-methodological principles;

- Participatory decision-making approaches;

- Locally relevant and culturally appropriate criteria;

- Approaches interconnecting local content with global and vice versa.

The revision process involved the determination of the most appropriate teaching and learning activities for each class session to facilitate the student learning. For example, the activities could be lectures, small group discussions, independent work, simulations, debates, case studies, role playing, demonstrations, experiential learning activities, instructional technologies, or collaborative learning work.

\section{Background of the Revision Process and Context of the Peer Review at University 2}

The participants from University 2 revised their courses according to the syllabus template that was available from the RUCAS Community of Practice (2013) website. This template consisted of information about:

1. Instructor, such as: instructor's name and title, office location, telephone, office hours, e-mail, and website;

2. Course identifications, such as: course number, course title, course location, class times, prerequisites, and faculty web page;

3. Course description;

4. Course learning objectives;

5. Course content leaning outcomes;

6. Course resources;

7. Assignments and grading scheme;

8. Grading policy;

9. Course schedule.

The members of the team conducted several face-to-face meetings to discuss in depth the process of developing their own syllabi. During those meetings, they shared their 
ideas and provided rich suggestions on how to integrate sustainability content, skills, and competences into the existing courses to address sustainability areas. After preparing the first draft of the syllabi, the members shared the syllabi with each other and got feedback.

The next step in the peer review was during the $2^{\text {nd }}$ RUCAS regional workshop that was held in Cairo. The main aim of it was to finalise the revised course syllabi. University 2 participated with eleven syllabi from various disciplines of educational sciences, pharmacy, engineering, and business/economic sciences. During the workshop events, teaching staff from Egypt, Jordan, and Lebanon discussed and reflected on the revised syllabi that each member of the RUCAS Community of Practice had developed to infuse sustainability concepts in his/her institutional undergraduate curricula. Furthermore, experts from European Union universities, the National Tempus Office in Egypt, the UNESCO Regional Office in Beirut and the UNESCO Office in Cairo contributed to the peer review of the syllabi.

At University 2, the implementation of the revised syllabi started during the spring semester of the academic year 2011-2012. Many constraints were faced by the teaching staff, such as working with a large number of students, which was one of the main obstacles. The professors were able to overcome the obstacles with patience, hope, and strong will. In the beginning, it was hard due to several duties, but later on things went smoothly and every student knew what s/he was supposed to do and how to work. Another constraint was communicating with the local community foundations and institutions. Some administrations were not cooperative with the students and were not willing to let them in at all. Therefore, the university staff tried to speak to the administrations and explain the assignment. Sometimes the university had to write an official letter to the local community foundations and institutions for developing the collaboration. Some students had full schedules so that they were not able to finish all the assignments, which required field visits. The solution to this problem was giving the students many assignments and letting them decide what to choose based on their convenience. Classroom physical setting was also a problem especially for conducting group discussion, because the seats were stable but sometimes we announced to the students that we had to move to another classroom where we could remove and change the setting. Furthermore, some students were not used to this type of learning but later on they enjoyed it.

One of the methods used for improving the skills of the teaching staff during the RUCAS project was peer review of teaching. Peer review of teaching is an established technique for improving teaching and promoting professional development of professors.

\section{Peer Review of Teaching}

In recent years, teaching at the university has become more and more complex and required several skills, which include not only the knowledge of the discipline, but also mastering teaching techniques and methods. This situation determines the basic needs for the teachers to have support and a professional comparison in order to obtain a suitable level of their teaching skills. This is a crucial issue, which is related to the discussion of the more appropriate models to enrich the teaching quality standards. Recently, several approaches have been developed to promote the professional development of faculty staff based on peer review of teaching, which involves comparison and interaction with colleagues. 
With regard to peer review definitions, there are different approaches and techniques (Buchanan \& Stern, 2012), and for this reason it is difficult to give a precise definition. Several terms with a similar meaning are often used, such as peer evaluation, peer assessment, peer review, peer observation, and it is difficult to determine the precise differences among them. Lomas and Nicholls (2005) defined peer review of teaching as an intentional process with the aim to provide feedback as a "critical friend". Peer review of teaching includes techniques based on peer collaboration and mutual respect rather than establishing dynamics of domination and superiority. During peer review, teaching styles and teaching plans are considered with constructive purposes, aiming to improve the quality of teaching. Feedback is based on a positive attitude analysing how to improve teaching strategies with the assumption to offer precious information for further didactic development. Such kind of positive feedback is usually considered valuable and inspiring.

With regard to the university context, there are several ways for developing peer review of teaching, which includes observations and discussions. However, only a few approaches have been assessed in order to determine the strengths and weaknesses of peer review of teaching. Tighe and Bradshaw (2013) reported three main models of peer review: an evaluation model, a developmental model and a collaborative model. The evaluation model is based on the assessment and "include appraisal to confirm probation, to identify under performance, for promotion purposes and as a quality assurance tool". It is performed by an expert, who could be a faculty senior member and observe the colleague during teaching. With regard to the developmental model, it aims to improve teaching skills rather than only assess them, and it is based on professional development. The performer of the developmental model may be a teaching administrative official or an external expert. With regard to the collaborative model, "the observation is usually a mutual and reciprocal process, whereby both parties observe each other's teaching and provide feedback which prompts dialogue and reflection. Aims of this model include to promote dialogue and discourse about teaching between peers, to stimulate innovation and to offer an opportunity for reflection." (Tighe and Bradshaw, 2013, p. 1348). The collaborative model of peer review comprises the following three main phases:

"The pre-observation meeting, the observation of teaching and the postobservation meeting. The pre-observation meeting provides both participants with an opportunity to establish trust and clarify the purpose of the observation, deal with any anxieties, discuss involvement of students and agree timing of feedback. This meeting provides both individuals with time to prepare for the process through dialogue about expectations. The role of observer also carries responsibilities in relation to providing confidential early feedback in a manner that is supportive, valuable and identifies areas for improvement. Equality, mutuality and reflection are at the heart of a collaborative model of peer supported review of teaching. The observation of teaching is just one stage in the process; however it often gets the most recognition. Finally, the post-observation meeting is central to the model whereby both observed and observer discuss, analyse and reflect on the process and identify strengths and areas for improvement. A crucial part of the process is the discussion and feedback afterwards." (Tighe and Bradshaw, 2013, p. 1348). 
With regard to the strengths of peer review, Lomas and Nicholls (2005) in a case study found that university staff considered praiseworthy the collaborative peer review process for the possibility it offered them to think over their didactic activities. Peer review is connected with the reflective teacher paradigm proposed by Schön (1983), which is based on the teacher ability to reflect on their informal dimensions and their intuitive knowing. Peer observation develops the practice of reflection, enhancing metacognitive strategies and determining an individual growth and professional development as a teacher. Self-reflection practices promote a constructive learning environment based on support and collaboration through dialogue. Peer collaboration is an important aspect of the teacher profile and may offer support to beginner teachers, for developing their teaching strategies and their confidence in teaching.

\section{The Current Research}

\section{Aims and Research Questions}

Based on the background of the revision process and course implementation at two Jordanian universities the current study presents the assessment of the revised curricula verifying how the ESD principles were infused. The evaluation processes employed quantitative and qualitative data collection techniques. However, for the purposes of this study only the quantitative data are presented. With regard to the revised courses, the following research questions were considered:

What were the most relevant ESD themes?

What were the most relevant ESD topics?

What were the most relevant ESD pillars (competencies)?

What were the most relevant ESD principles?

A specific questionnaire was built to analyse the revised courses.

\section{Method}

To assess the progress in reorienting university curricula to address sustainability, a quantitative study design was used in the framework of the peer review models described above. Data were collected with a tool to perform a quantitative evaluation of specific aspects of the revised syllabi.

\section{Procedure and Participants}

The revised syllabi were sent via email to the evaluator enabling him to acquire a high level of familiarity with the topics and to develop the first draft of the assessment. The following seven syllabi were sent by University 1: applied developmental biology, concepts and methods of teaching biology, elementary science methods, multimedia programming, teaching science, the environment and community, and tissue culture.

The following 11 syllabi were sent by University 2: applied chromatography, designing and producing instructional materials, financial analysis, instrumental analysis, instructional materials for children, international finance, math concepts for generalist-2, medicinal chemistry-3 A, medicinal chemistry-3 B, metallurgical processes, properties of engineering lab. 
After about one month of sending the syllabi, there were meetings held with four professors from University 1 and four professors from University 2. The four professors from University 1 were two males and two females and were teaching the following topics: biology, science teaching, and multimedia programming. The four professors from University 2 were one male and three females and were teaching the following topics: math teaching, international finance, finance analysis and multimedia programming. During the meetings, the revised syllabi were discussed with the aim to verify how the ESD principles were infused. In addition, meetings were an occasion for discussing teaching methods, principles, didactic processes and practices in ESD curriculum design in higher education.

\section{The Assessment Tool}

The Assessment Template (AT) was used as an assessment tool in the current research (see Appendix 1). The AT was developed by the research team directed by Prof. Makrakis within the framework of the RUCAS project. The AT was developed to assess the revised courses as a tool for self-peer-external assessment. The theoretical background of the AT is based on the reflective teacher paradigm by Schön (1983), in which the professors have to reflect on the processes involved in teaching/learning and not to consider teaching merely as a product. In this framework, teaching could be constantly further revised and improved, and critical reflection became the main instrument to ameliorate the quality of teaching. Critical reflection is a crucial activity, in which the instructor thinks upon his experiences, defining the strengths and the weaknesses of his actions. It is also a tool for developing metacognitive strategies and the control over the teaching actions (Biasutti, 2012, 2013, 2015; Biasutti \& Frate, in press). The application of the reflective practice in ESD could be a method for implementing a dynamic transformation, in which the ESD principles are used as a driving force for curriculum planning.

The AT is composed of several parts, including quantitative and qualitative questions. The first part is composed of general questions such as a name of course instructor, course title, institution, country, name of the evaluator, and institution. The main quantitative part of the questionnaire is composed of the following five sections:

1. ESD themes;

2. ESD competencies;

3. Teaching strategies;

4. Assessment alignment;

5. ESD critical principles.

Section 1 is composed of two parts. The first part included the following themes: scale, human connections to the physical and natural world, ethics and values, functioning of natural systems, technological and economic relationships to development, motivating sustainable behaviour and pedagogical strategies for integrating sustainability. The second part is composed of the following topics: natural resource management (water, forest, agriculture, biodiversity), climate change, disaster prevention and mitigation, energy management, citizen participation and good governance, wellbeing and poverty reduction, indigenous knowledge and ethnic groups, sustainable urbanisation, sustainable production/consumption, cultural diversity, gender equality, peace and human security, health promotion, human rights, sustainable agriculture, corporate responsibility and other theme (please specify). It was asked to tick the box if the ESD theme was integrated 
in the revised course and to indicate the percentage of the revised course that addressed each theme (0-100\%).

In Section 2, it was asked to insert the course learning outcomes from the revised course and to tick if the five ESD competencies (1. Learning to Know; 2. Learning to Do; 3. Learning to Be; 4. Learning to Live Together; 5. Learning to Transform Oneself and Society) were explicitly or implicitly addressed by the learning outcomes within the revised course. In addition, the degree of the expected overall mastery of each competency should be evaluated according to a three-level scale (low level, medium level or high level of integration).

In Section 3, it was asked to evaluate the teaching and learning strategies used within the revised course, and their frequency of use based on a 5-point Likert scale (not used at all, rarely used, used sometimes, used quite often, used very often). The task was closed since a list with the following teaching strategies was presented: lecturing, project-based learning, interactive engagement, case-based instruction, inquiry-based learning, interdisciplinary teaching, problem-based learning, tech-supported instruction, placed-based learning, discovery learning, role plays \& simulations, group discussion, stimulus activities, debates, critical incidents, case studies, reflective/reflexive accounts, fieldwork \& outdoor learning, modelling good practice. In addition, the following open question was presented: "Other: please detail any other teaching and learning strategy that has not been listed above here."

In Section 4, it was asked to indicate the different modes of assessment that had been used in the course, for example, examination, essay, project, portfolio, oral presentation, group presentation, etc. In addition, participants were asked to list the learning outcome/s that each mode of assessment was related to.

Section 5 included the following 11 ESD principles: 1: Emphasises system thinking; 2: Practised locally; 3: Extended globally; 4: Focuses on community; 5: Highlights connections; 6: Nurtures personal and social responsibility; 7: Fosters transformation; 8: Clarifies one's own values; 9: Envisions more positive and sustainable future; 10: Responds through applied learning; 11: Explores the dialectic between tradition and innovation. Two tasks were asked: to tick the box below if each critical principle was explicitly or implicitly integrated in the revised course and to explain how the ESD principle was addressed or was not addressed in the revised course.

The last part of the questionnaire was qualitative and comprised the following three sections:

6. Dimensions of Sustainable Development (Please explain how the four dimensions of Sustainability - Social, Environmental, Economic or Cultural - explicitly or implicitly were addressed within this revised course).

7. Critical reflection (Please summarise the recorded incidents applied for the formative assessment of the revised course during its implementation and the changes that occurred).

8. Overall suggestions (Please summarise the general proposed suggestions for the further improvement of the course revised).

These questions induced a range of qualitative comments by participants and offered a variety of insights into the strengths and weaknesses the ESD infusion process. 


\section{Results}

In this section, the data of the AT are presented addressing the four research questions described above. The quantitative data were analysed using descriptive statistics. For the purposes of this study, only the quantitative data are presented for sections 1) ESD themes and topics; 2) ESD competencies; and 5) ESD principles.

With regard to University 1 , seven revised syllabi within the disciplines of biology, science teaching, and multimedia programming were reviewed for the purpose of this interim evaluation. With regard to University 2, eleven revised syllabi within the disciplines of math teaching, international finance, finance analysis and multimedia programming were reviewed for the purpose of this interim evaluation. All courses have infused sustainability, some to a great extent. In the following sections, the details of this progress are reported.

ESD Theme Coverage. With regard to Section 1 (ESD themes), part one of the AT, the results are reported in Table 1 . As you can see in Table 1, for University 1 all the seven ESD themes are very well covered - only the themes "Functioning of natural systems" and "Technological and economic relationships to development" appear a bit less addressed.

For University 2, the ESD themes infused in the revised course covered a wide range of ESD themes across all the disciplines. The themes "Human connections to physical and natural world", "Ethics and values" and "Technological and economic relationship to development" are well addressed, while the theme "Functioning of natural systems" is less well addressed.

Table 1

ESD Themes Infused in the Revised Courses at the Two Universities

\begin{tabular}{lcc}
\hline \multicolumn{1}{c}{ ESD themes in the revised course } & University 1 & University 2 \\
\hline 1. Scale & 7 & 3 \\
\hline 2. Human connections to the physical and natural world & 7 & 6 \\
\hline 3. Ethics and values & 7 & 6 \\
\hline 4. Functioning of natural systems & 6 & 1 \\
\hline 5. Technological and economic relationships to development & 5 & 6 \\
\hline 6. Motivating sustainable behaviour & 7 & 3 \\
\hline 7. Pedagogical strategies for integrating sustainability & 7 & 4 \\
\hline
\end{tabular}

ESD Topic Coverage. With regard to Section 1 (ESD topics), part two of the AT, the results are reported in Table 2. As you can see in Table 2, for University 1 a wide range of ESD topics across all the disciplines were covered. Only the topic "Indigenous knowledge and ethnic groups" was not addressed at all by any course. Also for University 2 there is a wide range across the disciplines of ESD topics infused in the revised course and "Health promotion" and "Sustainable production/consumption" are the most well addressed. Only one of the ESD topics "Natural resource management (water, forest, agriculture, biodiversity)" was not considered by any of the revised courses at University 2 . 
Table 2

ESD Topics Infused in the Revised Courses at the Two Universities

\begin{tabular}{lcc}
\hline \multicolumn{1}{c}{ ESD topics } & University 1 & University 2 \\
\hline $\begin{array}{l}\text { 1. Natural resource management (water, forest, agriculture, } \\
\text { biodiversity) }\end{array}$ & 6 & 0 \\
\hline 2. Climate change, disaster prevention and mitigation & 5 & 1 \\
\hline 3. Energy management & 5 & 1 \\
\hline 4. Citizen participation and good governance & 6 & 2 \\
\hline 5. Wellbeing and poverty reduction & 5 & 1 \\
\hline 6. Indigenous knowledge and ethnic groups & 0 & 1 \\
\hline 7. Sustainable urbanization & 4 & 2 \\
\hline 8. Sustainable production/consumption & 4 & 5 \\
\hline 9. Cultural diversity & 6 & 2 \\
\hline 10. Gender equality & 4 & 1 \\
\hline 11. Peace and human security & 4 & 2 \\
\hline 12. Health promotion & 5 & 7 \\
\hline 13. Human rights & 5 & 2 \\
\hline 14. Sustainable agriculture & 3 & 2 \\
\hline 15. Corporate responsibility & 3 & 2 \\
\hline 16. Other themes & 0 & 2 \\
\hline
\end{tabular}

ESD Pillars of Learning. With regard to Section 2 (ESD competencies) of the AT, the results are reported in Table 3. As you can see in Table 3, for University 1 all the seven ESD pillars are very well covered with an emphasis on the first two pillars (learning to know and learning to do), which are the basic ones. At University 2, there is an emphasis on preparing learners to know and to do. There is less emphasis on preparing learning to reflect on its own value basis (learning to be), or on how learners can contribute to peaceably "live together", or on how learners can act as agents of change. It would be interesting to reflect upon the right strategies for developing such kind of processes within the specific topic. Defining the appropriate didactic methods is an important step for implementing these skills during the course.

Table 3

ESD Pillars Infused in the Revised Courses at the Two Universities

\begin{tabular}{lcc}
\hline \multicolumn{1}{c}{ ESD pillars infused in the revised course } & University 1 & University 2 \\
\hline 1. Learning to know & 7 & 11 \\
\hline 2. Learning to do & 7 & 11 \\
\hline 3. Learning to be & 6 & 8 \\
\hline 4. Learning to live together & 6 & 5 \\
\hline 5. Learning to transform oneself and society & 5 & 5 \\
\hline
\end{tabular}

ESD Principles. With regard to Section 5 (ESD critical principles) of the AT, the results are reported in Table 4 . As you can see in Table 4, there is a wide range of ESD principles that are covered across all the disciplines. For University 1 only the principle "highlights connections" is less addressed. The principles "focuses on community", "nurtures personal and social responsibility", "clarifies one's own values" and "envisions more positive and sustainable future" were addressed by all the courses. As far as Univer- 
sity 2 is concerned, the most addressed principles are "practised locally" and "responds through applied learning”, which are addressed by all the revised courses. The less addressed principles are "nurtures personal and social responsibility" and "clarifies one's own values", which are addressed by three courses.

Table 4

ESD Principles Infused in the Revised Courses at the Two Universities

\begin{tabular}{lcc}
\hline \multicolumn{1}{c}{ ESD principles infused in the revised course } & University 1 & University 2 \\
\hline 1. Emphasises system thinking & 4 & 10 \\
\hline 2. Practiced locally & 6 & 11 \\
\hline 3. Extended globally & 5 & 5 \\
\hline 4. Focuses on community & 7 & 4 \\
\hline 5. Highlights connections & 2 & 9 \\
\hline 6. Nurtures personal and social responsibility & 7 & 3 \\
\hline 7. Fosters transformation & 6 & 4 \\
\hline 8. Clarifies one's own values & 7 & 3 \\
\hline 9. Envisions more positive and sustainable future & 7 & 4 \\
\hline 10. Responds through applied learning & 5 & 11 \\
\hline 11. Explores the dialectic between tradition and innovation & 4 & 5 \\
\hline
\end{tabular}

Meetings with the professors at the two universities provided evidence of the great work done for infusing sustainability in their university curricula. There was evidence of the professors' awareness of their professional development as an effect in participating in the RUCAS project. The teaching staff members participating in the project were very well informed on relevance of sustainability within their respective disciplines. Many courses infused ethics and motivated sustainable behaviour. In discussions with management, there was a high degree of interest to the infusion of sustainability in all aspects of university life.

The overall conclusion is that the teaching staff demonstrated high awareness and skills necessary for infusing sustainability in their syllabi. This was not only from a theoretical perspective but also from an applied point of view, since many courses infused ethics and motivated sustainable behaviour. A general recommendation is to continue working in this direction and involve more colleagues in the process of curricula revision.

With regard to the general areas for improvement, there were the following other issues:

- There were differences in the syllabi concerning the number of course learning objectives: probably too many in some cases. Course learning objectives were linked to assessment; measurable, evaluable, clear and specific objectives helped define the assessment phase;

- Assignment brief had to be more detailed in the syllabi;

- In a few cases, the course overview informed that sustainability was infused, but not listed within the learning outcomes or detailed in the course schedule. This was made clearer in discussions with the teaching staff;

- The scheduled course needed to be more detailed (topics);

- Four syllabi had the "course description/overview" section in the Arab language and could not be understood; 
- The way of involving students in reflection on the importance of ESD principles and the process of their application in the future profession;

- Supporting students to develop the metacognitive skills for becoming conscious transformation agents of self and society.

\section{Discussion}

Several aspects emerged from the assessment using the AT questionnaire. With respect to Section 1, part one (ESD themes) of the AT, the results showed that the themes of "Human connection to physical and natural world", "Ethics and values", "Pedagogical strategies for integrating sustainability" and "Technological and economic relationship to development" were well addressed by all the revised courses, whereas the theme of "Functioning of natural systems" was less addressed. This finding can be explained by the fact that the type of the revised courses is not directly related to the functions of the natural systems. As mentioned earlier, the revised courses were offered by the Faculty of Educational Sciences and the Faculty of Business and Administration. Furthermore, this result can be explained by the fact that ethics and values are very important in our lives (Frenz, 2012), especially as the vast amount of information and knowledge has become easily accessible through technological tools and resources. In addition, this result agrees with the findings of Moore's (2011) study dealing with ethics in education. Nowadays no one owns the knowledge. It is crucial to emphasise on ethics and values in the revised syllabi. The theme "Pedagogical strategies for integrating sustainability" was also highly considered probably because it was one of the relevant issues in this revision process. Technology has become essential in our daily life, starting from early age we notice that children are attached to technology. Many studies showed that using technology in teaching affected students' learning abilities and improved their motivation towards learning as well as helped students develop high level of thinking skills (Kapenieks, \& Salìte, 2012; Makrakis, Gkotzos, \& Larios, 2012; Makrakis, \& KostoulasMakrakis, 2012).

With respect to Section 1, part two (ESD topics) of the AT, the results indicated that "Health promotion" and "Sustainable production/consumption" were well addressed by all the syllabi. The reason could be because the revised courses were connected to human beings and their everyday lives, while the topic "Natural resource management" was not addressed. This could be explained by the fact that the nature of the course content where the topic "Natural resource management" was not addressed.

With respect to Section 2 (ESD competencies) of the AT, the most infused ESD pillars were "learning to know" and "learning to do". For Section 5 (ESD critical principles) of the AT, the results showed an emphasis on "practices locally", and "responds through Applied Learning" in all the syllabi. This could be explained by the fact that mastering skills (how to do) was very important for students seeking jobs after graduation. We can see that job market now focuses more on skills and competencies rather than on knowledge. Sisley (2010) stated that market needs changed dramatically due many reasons and education was one of those reasons. However, Franklin (2010) pointed out that skills were important to ease gaining a job. According to Madson (2013), we as instructors cannot demonstrate skills without introducing the basic knowledge about these skills. Moreover, students need to know the skills before learning how to practice them (Dembo, 2000). 
In this study, the AT was applied as an assessment tool for the revised syllabi. The results may vary or change when applying different instruments, such as interviewing selective students enrolled in the revised courses and asking them what they think of sustainability and what are the competencies that they have acquired from studying the revised courses. Another suggestion is using surveys such as the Attitudes toward Sustainable Development scale (Biasutti and Frate, in press) to collect data from the students enrolled in the revised courses for triangulating the results. We can also analyse students' assignments, projects, and/or portfolios to examine how they reflect on the ESD principles. Furthermore, we can conduct several visits to the local community foundations and collect information regarding infusing sustainability into the curriculum.

Instruction should be constantly revised and improved based on critical reflective practices. The AT questionnaire appeared to be a viable instrument that could be used for self-peer-external assessment where the instructors could be able to reflect on their teaching/learning processes. The AT measures the extent to which the following variables have been considered during the course instruction, namely: ESD themes and topics, ESD competencies, learning strategies, assessment alignment, ESD critical principles, in addition to three open questions.

The instrument proved to be a convenient indicator for measuring strengths and weaknesses of the instructors' teaching/learning practices. From this perspective, incorporating ESD concepts and principles into the curricula should be a major concern for today's higher education institutions. Through adopting the framework of the RUCAS project, the infusion of the principles of sustainable development could be improved and expanded. Thus, the practices and policies of several courses offered at both universities, as related to sustainability, could be modified and amended.

\section{Conclusion}

The current study presents the peer assessment process of the revised syllabi for infusing ESD principles by professors at two Jordanian universities. The AT was used as the main tool for conducting the assessment. During the meetings teaching methods, principles, didactic processes, and practices in ESD curriculum design and revision for higher education were discussed. The peer review was an opportunity to reflect and discuss syllabi development, as well as refine teaching methods for university lessons. The meetings with the professors provided evidence of all the great work accomplished for infusing sustainability in the revised courses at the two Jordanian universities. Findings offered a rich scenario of the strategies engaged by professors in revising the curricula, providing evidence of a mental attitude in adopting metacognitive strategies as well as a goal-oriented approach in curriculum planning.

With regard to the further development of the research, it is interesting to apply a pre-post research design, in which the AT and other surveys are administered before and after the syllabus revision. This procedure allows the researchers to compare the results in the two conditions and to verify with statistical analysis the progress in revising the syllabi. In conclusion, the experience of both universities participating in the RUCAS project can lead the way in developing the strategies and tools for infusing sustainability concepts and principles into the curricula, and provide a benchmark for other universities in Jordan. 


\section{Acknowledgment}

The present research has been conducted within the framework of the RUCAS (Reorient University Curricula to Address Sustainability) project that has been funded with support from the European Commission (European Commission, TEMPUS - No 511118-2010-GR-JPCR). The content of the paper reflects the views of the authors, and the Commission cannot be held responsible for any use which may be made of the information contained therein.

Authors' contribution: MB was the originator of the idea of the paper, who made the literature review, data analysis, result interpretation and wrote the paper; TDB undertook the literature review, RUCAS actions and described the revision process; HA undertook the literature review, RUCAS actions and described the revision process.

\section{References}

Biasutti, M. (2012). Beliefs about teaching music: A comparison between primary and secondary trainee teachers. Journal of Education for Teaching: International research and pedagogy, 38 (3), 231-244.

Biasutti, M. (2013). Improvisation in dance education: teachers views. Research in Dance Education, 14 (2), 120-140.

Biasutti, M. (2015). An intensive programme on education for sustainable development: The participants' experience. Environmental Education Research, 21(5), 734-752.

Biasutti, M. \& Frate S. (in press). A validity and reliability study of the Attitudes toward Sustainable Development scale. Environmental Education Research,

Biasutti, M., Surian A. (2012). The Student survey of Education for Sustainable Development Competencies: a comparison among Faculties. Discourse and Communication for Sustainable Education, 3 (1), 75-82.

Buchanan, M.T. \& Stern, J. (2012) Pre-service teachers' perceptions of the benefits of peer review. Journal of Education for Teaching: International research and pedagogy, 38(1), 37-49.

Delors, J. (1996). Learning: The treasure within. Report to UNESCO of the International Commission on Education for the Twenty-first Century. Paris: UNESCO Publishing.

Dembo, M. (2000). Motivation and learning strategies for college success. Lawrence Erlbaum Associates, London

Franklin, J. (2010). Learning for work. New York: Columbia University Press.

Frenz, R. (2012). Importance of ethics and moral. Justice Press. NY

Kapenieks, J., \& Salite, I. (2012). Action research for creating knowledge in an e-learning environment. Journal of Teacher Education for Sustainability, 14(2), 111-129.

Kostoulas-Makrakis, N. (2010). Developing and applying a critical and transformative model to address ESD in teacher education. Journal of Teacher Education for Sustainability, 12(2), 17-26.

Lomas, L., \& Nicholls, G., (2005). Enhancing teaching quality through peer review of teaching. Quality in Higher Education, 11 (2), 137-149.

Madson, M. (2013). The Importance of Teaching Skills. Retrieved September 25, 2013, from http://www.apa.org/gradpsych/2006/03/corner.aspx

Makrakis, V., Gkotzos, D., \& Larios, N. (2012). ICT-Enabled Climate Change Education and Children Rights. Journal of Teacher Education for Sustainability, 14(2), 89-110. 
Makrakis, V., \& Kostoulas-Makrakis, N. (2012). Course curricular design and development of the M.Sc. programme in the field of ICT in education for sustainable development. Journal of Teacher Education for Sustainability, 14(2), 5-40. doi: 10.2478/v10099-012-0007-7

Moore, S. (2011). Ethics in education. Review of Research in Education, 26(3), 31-59.

Pipere, A., Veisson, M., \& Salīte, I. (2015). Developing research in teacher education for sustainability: UN DESD via the Journal of Teacher Education for Sustainability. Journal of Teacher Education for Sustainability, 17(2), 5-43.

RUCAS Community of Practice (CoP) (2013) Retrieved September 7, 2013, from http://community.cc.uoc.gr)

RUCAS (Reorient University Curricula to Address Sustainability). (2012). Mediterranean Education Initiative for Environment and Sustainability (MEdiES). Retrieved September 7, 2013, from http://www.medies.net/staticpages.asp?aID=567\&over RideCategory $=1$

Schön, D. (1983) The reflective practitioner: How professionals think in action. London: Temple Smith.

Sisley, L. (2010). Market needs. Haward Press, WV.

Tighe, S.M., \& Bradshaw C. (2013). Peer-supported review of teaching: Making the grade in midwifery and nursing education. Nurse Education Today, 33, 13471351.

UNESCO (United Nations Educational, Scientific and Cultural Organization). (2005). United Nations Decade of Education for Sustainable Development (2005-2014): International implementation scheme. Retrieved September 7, 2013, from http://unesdoc.unesco.org/images/0014/001486/148654e.pdf

UNESCO (United Nations Educational, Scientific and Cultural Organisation). (2011). Five pillars of ESD. Retrieved September 6, 2013, from http://portal.unesco.org/ geography/en/ev.php-URL_ID=14132\&URL_DO=DO_TOPIC\&URL_SECTION= 201.html

Correspondence concerning this paper should be addressed to Michele Biasutti Ph.D, Associate Professor FISPPA University of Padova, Via 8 Febbraio, 2 - 35122 Padova, Italy. Email: michele.biasutti@unipd.it

Appendix 1. The Assessment Template

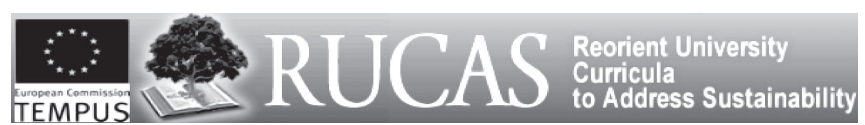

\section{Assessment Template}

INSTRUCTIONS: This template should be used for each revised course as a tool for self-peer-external assessment. Viewing curriculum as a process and praxis and not merely as a product implies among other things that what we are being teaching can be further revised and improved. In this context, critical reflection is an important human activity in which people recapture their experience, think about it, mull it over and evaluate it. It is working with experience that is important in learning. In education for sustainability, 
seeing it from a transformative perspective, reflective practice is applied widely, referring to the process of the educator studying his or her own teaching methods and content and determining what works best for the students. Often there is a requirement to reflect on practice, which can be traced back to the work of John Dewey (felt need) and Donald Schön (reflective practice), both of whom put forward the notion that reflection is a critical underpinning of growth and learning. Donald Schön's 1983 book introduces concepts such as "reflection on action" and "reflection in-action" 1 , read about it. Interactive introspection (reflexive practice) is an effective tool used to improve our courses while being tried out. As discussed in the Cairo workshop, keeping a journal; seeking feedback; viewing experiences objectively; and taking time to reflect-on-actions should be applied. Thus, in the self-assessment template summarise in the space provided at the end all those thoughts, processes and actions taken to improve your course during its implementation.

Good Luck

Vassilios Makrakis: Project Coordinator

Name of course instructor:

Institution:

Name of the evaluator:
Course Title:

Country:

Institution:

1. ESD Themes (Please tick the ESD themes that are explicitly or implicitly addressed within your revised course)

\begin{tabular}{|c|c|c|}
\hline \multicolumn{3}{|c|}{ ESD Themes Infused in the Revised Course } \\
\hline ESD Theme & $\begin{array}{l}\text { Please tick the box } \\
\text { below if this theme } \\
\text { is integrated in } \\
\text { the revised course }\end{array}$ & $\begin{array}{l}\text { Please indicate the percentage } \\
\text { of the revised course that } \\
\text { addresses each theme } \\
(0-100 \%)\end{array}$ \\
\hline Scale $^{2}$ & - & \\
\hline $\begin{array}{l}\text { Human connections to the physical } \\
\text { and natural world }\end{array}$ & - & \\
\hline Ethics and values ${ }^{4}$ & - & \\
\hline Functioning of natural systems ${ }^{5}$ & - & \\
\hline $\begin{array}{l}\text { Technological and economic } \\
\text { relationships to development }{ }^{6}\end{array}$ & - & \\
\hline Motivating sustainable behaviour ${ }^{7}$ & - & \\
\hline $\begin{array}{l}\text { Pedagogical strategies for } \\
\text { integrating sustainability }\end{array}$ & - & \\
\hline
\end{tabular}

1 For a quick further reading on critical reflection look at http://en.wikipedia.org/wiki/Reflective_ practice and the cited references. Further literature on critical reflection and reflexive practice will be uploaded in the CoP.

2 'Scale' refers to consideration within the course of Local/ Global impacts, and or intergenerational impacts, of human action. 


\section{ESD Themes Infused in the Revised Course}

\begin{tabular}{|c|c|c|}
\hline ESD Theme & $\begin{array}{l}\text { Please tick the box } \\
\text { below if this theme } \\
\text { is integrated in } \\
\text { the revised course }\end{array}$ & $\begin{array}{l}\text { Please indicate the percentage } \\
\text { of the revised course that } \\
\text { addresses each theme } \\
(0-100 \%)\end{array}$ \\
\hline $\begin{array}{l}\text { Natural resource management (water, } \\
\text { forest, agriculture, biodiversity) }\end{array}$ & - & \\
\hline $\begin{array}{l}\text { Climate change, disaster prevention } \\
\text { and mitigation }\end{array}$ & - & \\
\hline Energy management & - & \\
\hline $\begin{array}{l}\text { Citizen participation and good } \\
\text { governance }\end{array}$ & - & \\
\hline Wellbeing and poverty reduction & - & \\
\hline $\begin{array}{l}\text { Indigenous knowledge and ethnic } \\
\text { groups }\end{array}$ & - & \\
\hline Sustainable urbanisation & - & \\
\hline Sustainable production/consumption & - & \\
\hline Cultural diversity & - & \\
\hline Gender equality & - & \\
\hline Peace and human security & - & \\
\hline Health promotion & - & \\
\hline Human rights & - & \\
\hline Sustainable agriculture & - & \\
\hline Corporate responsibility & - & \\
\hline Other theme, please specify & - & \\
\hline
\end{tabular}

3 'Human Connections to Physical and Natural World' refers to consideration within the course of humans as part of nature $\&$ the effects of human activity on population, health, biosphere and our ability to sustain.

4 'Ethics and Values' refers to consideration within the course of how we can sustain equity, justice and societal well-being; an examination of our ethical-values base, our identity and how this impacts on others and bio-sphere.

5 'Functioning of Natural Systems' refers to consideration within the course of the natural laws that dictate how our earth's biosphere functions. It focuses on the holistic and interdependent nature of the ecosystem.

6 'Technological and economic relationships to development' refers to consideration within the course of technical, scientific and economic strategies that will foster sustainable development.

7 'Motivating Sustainable Behaviour' refers to consideration within the course of how sustainable behaviour patterns can be motivated, activated and sustained.

8 'Pedagogical Strategies for Integrating Sustainability' refers to consideration within the course of the different approaches and strategies to teaching, learning and assessment that help integrate and promote sustainability. 
2. ESD Competencies (Please tick the ESD competencies explicitly or implicitly addressed by the learning outcomes within this revised course, and the degree of expected overall mastery of each competency: low level, medium level or high level of integration)

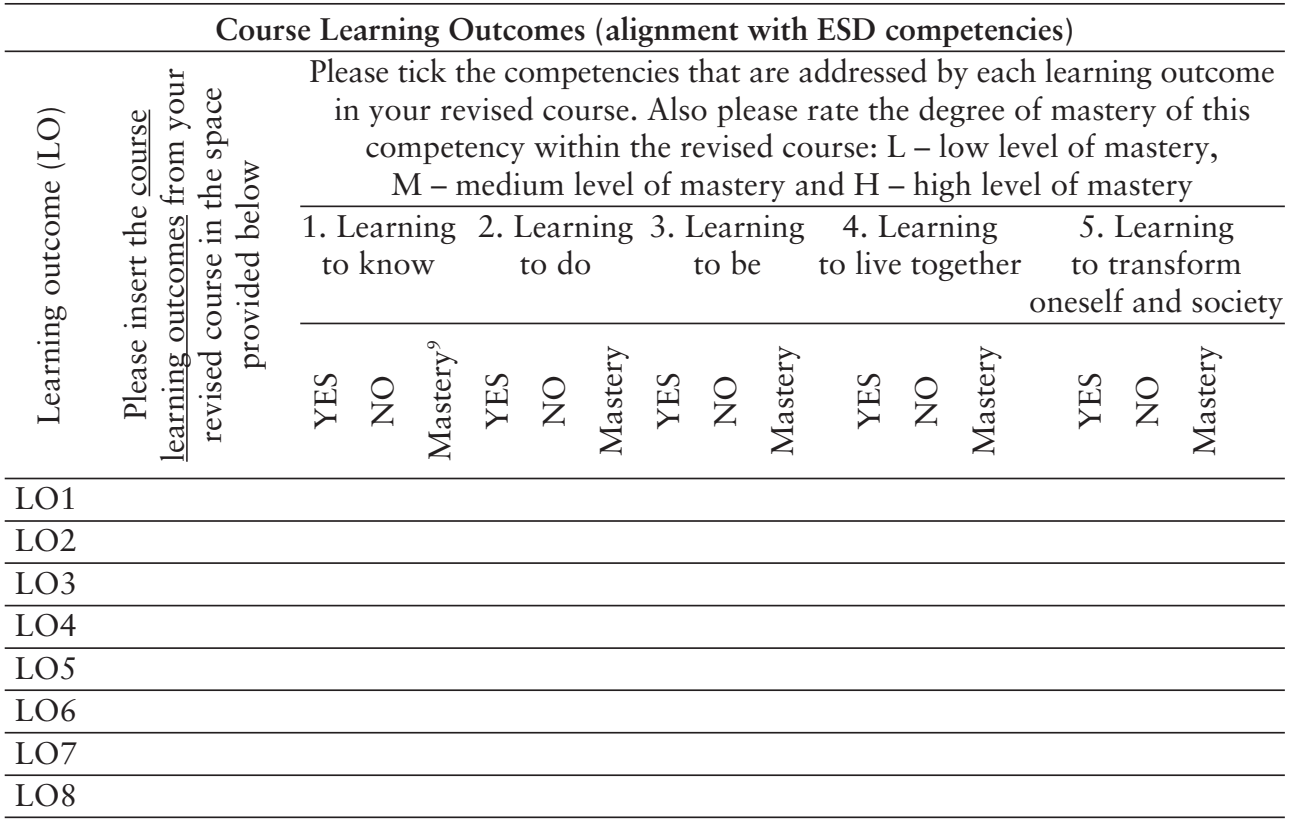

3. Teaching Strategies (Please indicate the main teaching and learning strategies used within this revised course, and their frequency of use)

Teaching and Learning Strategies

Please tick the frequency of use of each teaching and learning strategy in the revised course

Teaching and learning strategy

\begin{tabular}{|c|c|c|c|c|}
\hline 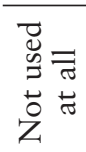 & 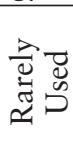 & 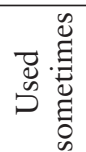 & 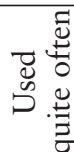 & 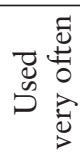 \\
\hline 1 & 2 & 3 & 4 & 5 \\
\hline
\end{tabular}

Lecturing (the instructor transmits knowledge and dispenses wisdom in the classroom and the students listen and take notes)

Project-based learning (the instructor engages students in activities designed to answer a question or solve a problem in the everyday world outside the classroom)

Interactive engagement (the instructor involves students in activities that yield immediate feedback through group discussion with peers and/or instructor)

Sequel to Table see on the next page.

9 Please rate the degree of Mastery of this competency within the revised course: Low Level (L) of mastery, Medium level (M) of mastery, High Level $(\mathrm{H})$ of mastery. 
Sequel to Table.

$\begin{array}{lllll}1 & 2 & 3 & 4 & 5\end{array}$

Case-based instruction (the instructor provides students with real-life situations to explore and apply a range of theories, behaviours and information)

Inquiry-based learning (the instructor poses questions allowing students to search for information and learn on their own with guidance)

Interdisciplinary teaching (the instructor involves in teaching the integration or synthesis of information and knowledge from more than one subject)

Problem-based learning (the instructor presents students with a problem to solve it collaboratively and reflect on their experiences)

Tech-supported instruction (the instructor uses tools such as concept mapping, mind-tools, modelling, simulations, the Internet and other Web-based tools)

Placed-based learning (students are placed for voluntary

community/social service to merge theory with practice)

Discovery learning (the instructor allows students to explore and manipulate objects, wrestling with questions and controversies or performing experiments)

Role plays \& simulations

Group discussion

Stimulus activities

Debates

Critical incidents

Case studies

Reflective/ reflexive accounts

Fieldwork \& outdoor learning

Modelling good practice

Other: Please detail any other teaching and learning strategy that it is not listed above here:

4. Assessment Alignment (Please indicate which course learning outcomes your assessment addresses)

\section{Modes of Assessment}

Write down different modes of assessment that have been used. (For example, Examination/

Essay/Project/Portfolio/Oral presentation/ Group presentation, etc.)

List the learning outcome/s that each mode of assessment examines 
5. ESD Critical Principles (Please tick the ESD Critical Principles explicitly or implicitly addressed within this revised course)

\begin{tabular}{|c|c|c|}
\hline \multicolumn{3}{|c|}{ ESD Principles Infused in the Revised Course } \\
\hline ESD Critical Principles & $\begin{array}{l}\text { Please tick the box } \\
\text { below if this critical } \\
\text { principle is integrated } \\
\text { in the revised course }\end{array}$ & $\begin{array}{l}\text { Please explain how you have } \\
\text { addressed this ESD principle, } \\
\text { or why you have not } \\
\text { addressed this ESD critical } \\
\text { principle in the revised course }\end{array}$ \\
\hline Principle 1: Emphasises system thinking & - & \\
\hline Principle 2: Practiced Locally & - & \\
\hline Principle 3: Extended Globally & - & \\
\hline Principle 4: Focuses on Community & - & \\
\hline Principle 5: Highlights Connections & - & \\
\hline $\begin{array}{l}\text { Principle 6: Nurtures personal and } \\
\text { social responsibility }\end{array}$ & - & \\
\hline Principle 7: Fosters Transformation & - & \\
\hline Principle 8: Clarifies one's own values & - & \\
\hline $\begin{array}{l}\text { Principle 9: Envisions more positive and } \\
\text { sustainable future }\end{array}$ & - & \\
\hline $\begin{array}{l}\text { Principle 10: Responds through applied } \\
\text { learning }\end{array}$ & - & \\
\hline $\begin{array}{l}\text { Principle 11: Explores the dialectic } \\
\text { between tradition and innovation }\end{array}$ & - & \\
\hline
\end{tabular}

6. Dimensions of Sustainable Development (Please explain how the four dimensions of Sustainability - Social, Environmental, Economic or Cultural - explicitly or implicitly are addressed within this revised course)

Dimensions of Sustainable Development Infused in the Revised Course

7. Critical Reflection (Please summarise the recorded incidents applied for the formative assessment of the revised course during its implementation and the changes that occurred)

Changes Implemented during the Course Implementation

8. Overall Suggestions (Please summarise the general proposed suggestions for the further improvement of the course revised)

Overall Suggestions for the Revised and Implemented Course 